\section{Environment and health}

The director-general of the World Health Organisation, Dr Hiroshi Nakajima, has chosen the theme 'Environment and health' for World Health Day, which is on the 7 April 1990. The World Health Organisation intends to spotlight the measures that individuals, communities, and nations may take to halt further deterioration to the health of our planet because as he points out not only our own health but that of future generations depends on it. Among other things, he mentions the problems arising from pollution from cars and chemicals and the need to increase the number of trees planted. The safety of dumping sites requires particular attention, and he makes a plea for clearing up rubbish in everybody's area because this may harbour pests and diseases. Another point that he makes is the importance of educating children in the future, the proper storage of chemicals, and the importance of organising discussion on environmental priorities.

\section{Roche rheumatology award}

The first Roche rheumatology award has been presented to Dr Mark $R$ Edbrooke, who is a postdoctoral scientist in the molecular rheumatology section at the Clinical Research Centre in Harrow. The prize, which is worth $£ 10000$, will be awarded biennially and has been given to $\mathrm{Dr}$ Edbrooke for his outstanding scientific contribution to research into arthritis. Dr Edbrooke's research has been particularly in intracellular mechanisms by which interleukin 1 and interleukin 6 control gene expression for the major acute phase reactant, serum amyloid A (SAA).

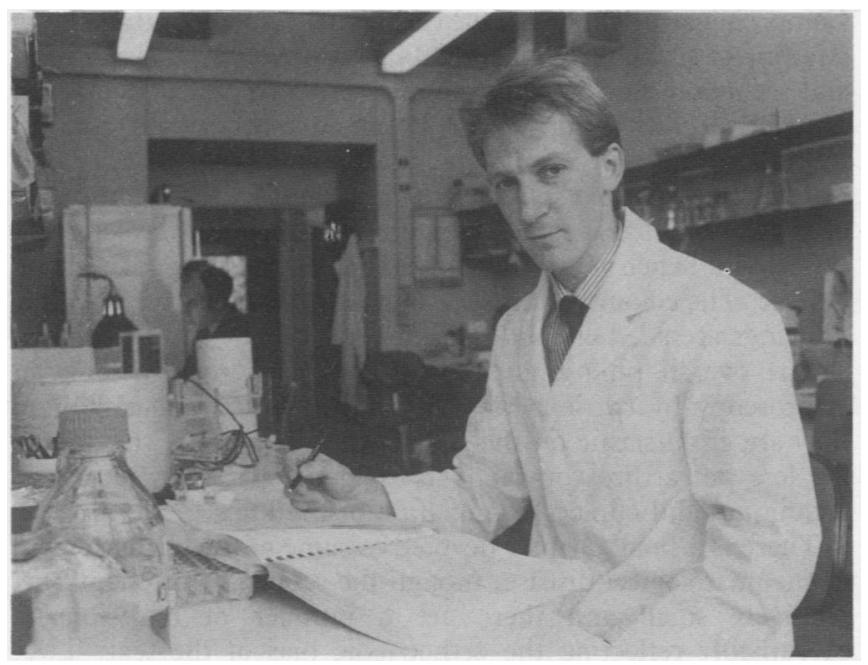

\section{Synovium-cartilage interrelationships: physiology and pathology in osteoarthritis}

An international symposium on 'Synovium-cartilage interrelationships: physiology and pathology in osteoarthritis' will be held in Bologna, Italy, from 21 to 24 May 1990. The official languages will be English and Italian.

Information may be obtained from Scientific Secretariat: Professor L Frizziero, Professor E Govoni, Unita' Operativa di Rheumatologia, Centro Traumatologico Ortopedico, Via Boldrini, 2-40121 Bologna, Italy.

\section{Metabolic bone diseases}

The first international symposium on metabolic bone diseases organised by the Spanish Society of Bone Investigation and Mineral Metabolism (SEIOMM) will take place from 8 to 11 October 1990 at the Platja d'Aro, Gerona, Spain. The official languages will be Spanish and English.

Selected topics are local factors in bone metabolism, tumoral hypercalcaemia, corticosteroid related osteoporosis, and bone diseases in renal failure.

For further information please contact: Secretaria del Primer Symposium sobre Enfermedades Oseas Metabolicas, Ganduxer 34, 08021 Barcelona, Spain.

\section{Musculoskeletal imaging}

The department of radiology, Hoag Memorial HospitalPresbyterian is presenting a course on musculoskeletal imaging from 23 to 25 July 1990 at the Ritz Carlton Resort Hotel, Laguna Niguel, California. The registration fee is $\$ 350$ for doctors and $\$ 200$ for residents, fellows, and technologists. The course will be accredited for $14 \% / 4$ hours in category 1 .

The course will concentrate on current whole-body musculoskeletal applications and clinical correlation. The programme director is Dr Joel Lipman.

For more information please contact: Dawne Ryals, Ryals \& Associates, PO Box 1925, Roswell, HA 30077-1925, USA. Tel (404) 641 9773. Fax (404) 5529859.

\section{Magnetic resonance imaging}

The department of radiology, Hoag Memorial HospitalPresbyterian is presenting the fourth annual symposium on magnetic resonance imaging from 26 to 29 July 1990 at the Ritz Carlton Resort Hotel, Laguna Niguel, California. The registration fee is $\$ 425$ for doctors and $\$ 300$ for residents, fellows, and technologists. The course will be accredited for two hours in category 1.

The symposium is directed at leaders in the field of magnetic resonance imaging and is designed to up date the clinician and radiologist on current $M R I$ use and introduce newer applications. The programme director is Michael Brant-Zawadzki.

For more information please contact: Dawne Ryals, Ryals \& Associates, PO Box 1925, Roswell, GA 30077-1925, USA. Tel (404) 6419773 . Fax (404) 5529859.

\section{Advanced imaging of the musculoskeletal system}

The department of radiology, University of California, San Diego School of Medicine is presenting a course on advanced imaging of the musculoskeletal system from 20 to 21 October 1990 at the Hotel del Coronado, Coronado (San Diego), California. The registration fee for the course is $\$ 175$ for doctors and $\$ 100$ for residents, fellows, and technologists. The course will be accredited for nine hours in category 1 by the Office of Continuing Medical Education in the Health Sciences of the University of California, San Diego School of Medicine.

The purpose of the course is to review the new advanced modalities available for imaging the musculoskeletal system, particularly emphasising magnetic resonance imaging, as well as providing an up date on computed tomography, densitometry, and bone biopsy. The program directors are Drs Sevil Kursunoglu-Grahme and Donald L Resnick.

For more detailed information please contact: Dawne Ryals, Ryals \& Associates, PO Box 1925, Roswell, GA 30077-1925, USA. Tel (404) 641 9773. Fax (404) 5529859. 